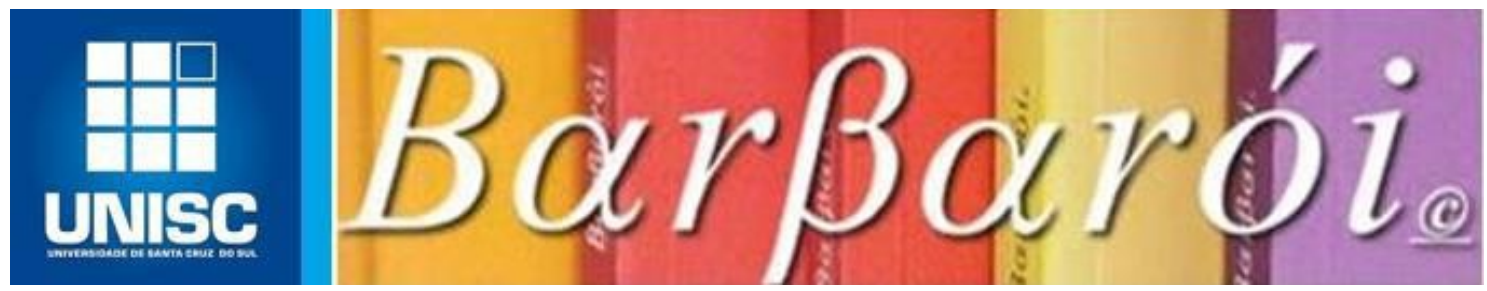

\title{
(AUTO)NARRATIVAS EM/NA FAMÍLIA: COGNIÇÃO E EMOÇÃO
}

\author{
DOI: http://dx.doi.org/10.17058/barbaroi.v0i0.14598
}

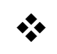

Maira Meira Pinto

Universidade de Santa Cruz do Sul-UNISC-Brasil

César Augusto Muller

Universidade de Santa Cruz do Sul-UNISC-Brasil

$$
*
$$

\section{Resumo}

A análise apresentada no presente artigo parte das ações desenvolvidas na pesquisa "Na ponta dos dedos: o IPAD como instrumento complexo de cognição/subjetivação", trazendo consigo os vetores teóricos do Grupo que executa a pesquisa, construídos a partir da convergência entre "educação e complexidade". Portanto, os entendimentos que configuram a análise vinculam-se ao Paradigma da Complexidade e à Teoria da Autopoiesis. A metodologia proposta é de cunho qualitativa, tendo como base a pesquisa intervenção, envolvendo os sujeitos que acompanham crianças com Transtornos do Espectro Autista (TEA). Os instrumentos utilizados foram as narrativas coletivas e autonarrativas como propulsores de intervenções, produzindo sentidos por meio das conversações formais e informais nos encontros presenciais. As ações descritas convergem para reflexões sobre o processo de aprendizagem de forma complexa, isto é, unindo as dimensões cognição/emoções, que foram cindidas e que marcam a cultura da modernidade. Ao final, o trabalho pretende contribuir para que as famílias possam (re)organizar-se a partir das reflexões sobre as vivências dentro de suas realidades/mundos.

Palavras-chave: Complexidade; auto-organização; cognição/emoções; autonarrativas; famílias; TEA.

\section{Introdução}

O presente estudo fez parte de um grupo de pesquisa de uma Universidade do interior do Rio Grande do Sul, que abriga a preocupação em unir as dimensões da realidade que foram cindidas pela modernidade. O artigo trabalha o relato e a análise de ações vinculadas ao projeto de pesquisa: Na ponta dos dedos: o IPad como instrumento complexo de cognição/subjetivação, que traz consigo os vetores teóricos do Grupo com o ponto de convergência "Educação e Complexidade". 
Por isso, este estudo visou experimentar as ações da vida para observar e compreender - em conjunto com os pesquisados -, a cognição/emoção e suas implicações ônticas e epistemológicas, por meio da Teoria da Autopoiesis e dos pressupostos do Paradigma da Complexidade, para uma educação (não formal e informal), profundamente vinculada à vida.

O projeto $\mathrm{Na}$ ponta dos dedos: o Ipad como instrumento complexo de cognição/subjetivação tem como foco o acoplamento do sujeito autista ao objeto técnico para desencadear processos cognitivos/afetivos. O quadro teórico sustenta, então, por meio do Paradigma da Complexidade, o entendimento do processo cognitivo/afetivo da criança diagnosticada com TEA (Transtornos do Espectro Autista), agregando ao estudo as questões de neuroplasticidade, apostando em processos auto-organizativos.

Por outro lado, em nosso País, há tempos, observa-se uma cultura profundamente estabelecida na abordagem do autismo que lida com reforços, repetições e automatismos num claro movimento oposto às condições autopoiéticas dos seres humanos. Considera também, essa pesquisa, que apesar de todos os avanços científicos do último século, em grande parte, graças à emergência de um novo paradigma complexo e do princípio da auto-organização, a educação em diversos níveis continua sendo não efetiva, podendo gerar perdas significativas de sentido existencial.

Portanto, o estudo aqui demonstrado, visou a inseparabilidade do aprender e viver $\left(1^{\mathrm{o}}\right.$ princípio da teoria da Autopoiesis), apostando unir cognição/emoção pela geração do conhecimento por meio da metodologia qualitativa, em especial, a pesquisa-intervenção. Neste sentido, pressupõe reflexões dos sujeitos pesquisados, pesquisadores e bolsistas como observadores incluídos ( $2^{\circ}$ princípio da teoria da Autopoiesis).

Para geração dos dados, utilizaram-se os seguintes métodos: narrativas coletivas e autonarrativas orais, diários de bordo e conversas formais e informais. Destacamos que a população alvo desta pesquisa foram os sujeitos que acompanham as crianças autistas atendidos pelo projeto IPad.

Os ambientes utilizados foram os espaços abertos da Universidade e outros espaços que se fizeram necessários, como as residências das famílias, por exemplo. Pode-se afirmar que, em razão da metodologia adotada, se estabeleceu uma aproximação entre o público-alvo dessa pesquisa e os pesquisadores e bolsistas, de forma que os processos desencadeados fizeram surgir e materializar a complexificação e a autopoiesis de todos os envolvidos, gerando reconhecimento da implicação num mesmo processo de aprendizagens. 


\section{Elementos Teóricos}

Os entendimentos que configuraram esta pesquisa vinculam-se ao Paradigma da Complexidade com o intuito de deflagrar um desdobramento da investigação Ipad, sem desarticular-se da problematização das investigações junto ao Grupo de Pesquisa mencionado na Introdução deste artigo. Nessa dinâmica, uma outra trama surgiu e, para melhor situar o leitor, configuramos brevemente, o contexto teórico investigativo.

Maturana e Varela (1995) consideram a autopoiesis como a capacidade de autoprodução dos seres vivos. Seres capazes de autoproduzir a si, e nessa dinâmica o conhecer é inseparável do viver.

[...] conhecimento se dá sempre num contexto relacional, em que as mudanças estruturais que as perturbações desencadeiam no organismo parecem ao observador como um efeito sobre o meio. É em relação aos efeitos esperados que o observador avalia as mudanças estruturais desencadeadas no organismo. Desse ponto de vista, toda interação de $\mathrm{m}$ organismo, toda conduta observada, pode ser avaliada por um observador como um ato cognitivo. Da mesma maneira, o viver - a conservação ininterrupta do acoplamento estrutural como ser vivo - é conhecer no âmbito do existir. Aforisticamente, viver é conhecer (viver é ação efetiva no existir como ser vivo) (MATURANA; VARELA, 1995, p. 201).

A máxima "viver é conhecer", e acrescentamos que, conhecer é viver, se configura por meio de um observador com capacidade operacional de aceitar suas ações como adequadas em um domínio especificado de ação. Compreende-se que a processualidade da complexificação do observador se instaurou, pois, muitos são/serão os domínios do emocionar quantos forem os domínios de ações co-ajustados entre observadores em conformidade "para aceitar certas ações como ações que definem e constituem um domínio cognitivo de critério de aceitabilidade que define e constitui esse domínio cognitivo" (MATURANA, 2006, p. 128).

Por meio desses entendimentos, buscamos junto aos pesquisados, experimentar as ações da vida, para poder conhecer, aprender e viver a Teoria da Autopoiesis. Também, pela afinidade da teoria, em conferir importância para unir e integrar o que foi cindido pelo paradigma mecanicista.

Disparar, propor perturbações, também vem sendo nossa intenção, a partir dos avanços já provocados pelas pesquisas, em especial as participativas, devido as suas críticas às concepções conservadoras que regem as ciências sociais e que estabelecem a separação da teoria e prática, neutralizando as ações dos envolvidos na pesquisa. Em outras palavras, rupturas, perturbações, conforme Stengers (2002), para o deslocamento da pretensão de saber/julgar; instaurar a desconfiança em relação as próprias palavras, às falas, aos pensamentos que poderiam explicar reduzindo as ações da vida. 
Dinâmicas complexas do provocar, tencionar, problematizar as palavras, falas, vozes, para se fazerem conhecer, denunciando, quem sabe, as aparências/representações que não se fazem perceptíveis. Por isso, as bases teórico-metodológicas que balizam o nosso projeto terão tons múltiplos para dar conta da complexificação dos pesquisados, pesquisadores e bolsistas, podendo instaurando, conforme Foucault (2010), um fora da ordem do discurso, um fora do tempo sucessivo - ou melhor, do que está dado, para somente ser representado.

Como consequência, a pesquisa consentiu importância às emoções, apesar de alguns filósofos da ciência e epistemólogos nos fazerem crer que o conhecimento é um processo construído através de uma lógica racional. Para esta pesquisa, foi um processo cognitivo/emocional, no qual as emoções consentem sentido imediato e global do mundo e da nossa situação nele.

Nessa perspectiva, Damásio (2000) traz contribuições importantes para entendermos a complexidade - e as implicações, do Sistema Nervoso Central - SNC, na configuração da dinâmica corporal/mental, fabricando estados cognitivo/emocionais. O autor destaca a complexidade, pois existem múltiplas ações, interações que são deflagradas pelas experiências que geram então, dinâmicas internas, bem como aprendizagens visando à regulação da vida.

Em outras palavras, as emoções são reações químicas e neurais complexas que balizam o papel regulador da vida, levando à fabricação de circunstâncias vantajosas ou não na auto-organização do sistema vivo, em função das particularidades que acompanham a experiência. Então, o papel das emoções é o de auxiliar o organismo a conservar a vida.

Por outro lado, os sentimentos Damásio (2000), são as percepções compostas pelo que ocorre em nosso corpo/mente quando uma emoção está em curso - devido às particularidades da experiência. Na verdade, no corpo, os sentimentos seriam imagens das ações por meio das percepções elaboradas pelos mapas cerebrais, revelando o estado de vida do organismo.

Salientamos que não são mapas corticais estáticos, e sim desenhos dinâmicos, progressivos em circularidade que se complexificam e que nos permitem o acesso online do que se sucede no cognitivo/emocional defronte à vida. Isto porque, o conhecimento humano como sendo a própria organização da experiência é, como está, não somente cognitiva e sim, também, motor, sensorial, perceptual e sobre tudo emocional. Quer isto dizer que as emoções não podem ser contrárias à razão ou somente instigadora dessa e sim, pelo contrário, primitivas e poderosas formas de conhecimento e acrescentamos, de aprendizagens. 
complexo de inúmeros circuitos cerebrais: a variedade de reações emocionais é responsável por mudanças profundas na paisagem do corpo e do cérebro. O conjunto dessas mudanças constitui o substrato para os padrões neurais que, em última instancia, se tornam sentimentos de emoção. (DAMÁSIO, 2000, p. 75)

De tal forma que o valor de atualização e acessibilidade do que se passa na corporeidade do cognitivo/emocional gera aprendizagens, sobre nós-outros e esses padrões organizativos - ações/atuações - complementam os nossos mapas mentais, para o melhor ou para o pior. Para melhor ou pior, pois vivemos, conforme Maturana e Verden-Zoller (2004), em uma cultura que valoriza a razão, racionalidade em detrimento das emoções, tornando-nos limitados e nos arriscamos a dizer, excluídos dos fundamentos biológicos dos modos de sermos humanos.

Por meio desses entendimentos, compreende-se que o autismo não é uma doença única, mas sim um distúrbio do desenvolvimento integral e, por sua vez, complexo. Isto porque, conforme Cavalcanti (2007, p.24 e 25), "nada mais difícil de conceituar que o autismo", devido às várias abordagens dadas tanto pela medicina quanto pela psicologia, "a neurologia descreve como uma síndrome (...) a psiquiatria divide-se entre a tendência a considerá-lo um distúrbio psico-afetivo ou uma doença geneticamente determinada".

Por outro lado, a autora salienta que no campo da psicologia há definições como "é uma defesa ante um encontro prematuro e traumático com o mundo externo que leva a criança a um retraimento profundo", ou que o autismo é "um modo específico de funcionamento mental que se distingue das psicoses infantis". Independente de qual definição, o projeto Ipad adota a seguinte compreensão: Transtorno do Espectro Autista - TEA é uma doença que ainda não tem cura e, segundo Gadia (2006, p.428) "não existe uma medicação específica para o autismo".

Por meio desse contexto, e a partir de estudos sobre aprendizagem no espaço digital, que apontam para um processo cognitivo complexo, no sentido de uma integração potencializadora do conhecer/subjetivar-se é que o projeto, "Na ponta dos dedos: o Ipad como instrumento complexo de cognição/subjetivação", formula seu problema central de pesquisa: Ao observar crianças com diferentes dificuldades de aprendizagem, incluindo algumas autistas, sinalizamos algumas transformações significativas em termos cognitivos e subjetivos. Como podemos explicar tal mobilização?

Portanto, a reflexão principal do presente artigo/projeto foi como o sujeito que acompanha a criança autista constrói seu sentido de mundo/realidade, para dar conta das contingências implicadas para aprender a viver outras relações cognitivo/emocionais.

Após o recebimento do diagnóstico de TEA, tende a família a passar por períodos de 
sofrimento? Os pais interrompem os seus afazeres profissionais para se dedicarem ao seu filho? É comum se perceber abalos emocionais entre estes familiares?

\section{Metodologia}

O fluxo metodológico balizador foi a pesquisa-intervenção que, conforme Rocha (1999), instaurou conexões e compreensões entre prática/teoria, viabilizando o aprender a aprender, saber-fazer e fazer-saber (PASSOS; BARROS, 2012), permitindo ir para além de admitir as implicações dos pesquisadores/pesquisados - já que para nós, toda pesquisa tem implicação.

\footnotetext{
Não se vai a campo e tampouco se constrói o diário dele sem que o corpo do investigador torne-se inteiramente implicado na tarefa, a ponto de, na conexão com outros corpos, perder todas as suas referências pontuais de originalidade. [...] Nesse modo de investigar, expõe-se precisamente a cenografia de uma empresa coletiva. [...] mas nunca de uma ação colegiada, no sentido totalizador do termo, já que implica a manutenção da diferença dos elementos envolvidos. (SOUZA, 2012, p. 29)
}

Implicados, sim, pois de acordo com a cibernética de segunda ordem, não existe a ilusão de acontecer observação sem um observador (MATURANA, 2006), e não existe uma realidade objetiva exterior a ser observada independente da ação do sujeito observador. Sujeito e mundo/realidade emergem simultaneamente por meio das ações e atuações do sujeito. Todos coautores no processo dessa pesquisa-intervenção, pois nesse sentido, não poderemos supor saber de antemão acerca da realidade a ser investigada.

Outra noção importante para nós pesquisadores, conforme Passos e Barros (2000), é que a pesquisa-intervenção não se trata de eliminar ações, mas sim, de perturbá-las, provocálas para problematizar práticas voltadas à produção de regimes de verdade. Até porque, "a direção de que se trata nesse método é aquela que busca aceder aos processos, ao que se passa entre os estados ou formas instituídas, ao que está cheio de energia potencial". (PASSOS; BARROS, 2012, p. 20)

A metodologia proposta envolveu os sujeitos que acompanham as crianças autistas, por meio do vínculo com o Projeto Ipad, junto ao Grupo de Pesquisa. Esta pesquisa possuiu também na sua tessitura relacional, além dos pesquisadores, dois bolsistas de iniciação científica - PIBIC-CNPq e PUIC ${ }^{1}$.

\footnotetext{
${ }^{1}$ O Programa UNISC de Iniciação Científica - PUIC, concede bolsa de iniciação científica por período de até 10 meses, para discentes de cursos de graduação da Universidade de Santa Cruz do Sul - UNISC desenvolverem atividades de iniciação à pesquisa, com dedicação de até 20 horas semanais, sob a orientação de docentes da Instituição. Outrossim, a Pró - Reitoria de Pesquisa e Pós-Graduação - PROPPG - da Universidade de Santa Cruz do Sul, também propicia abertura de edital para inscrições visando à seleção de candidatos às bolsas do Programa Institucional de Bolsas de Iniciação Científica - PIBIC, do CNPq - Conselho Nacional de Desenvolvimento Científico e Tecnológico, em conformidade com a Resolução Normativa 017/2006 do CNPq.
} Barbarói, Santa Cruz do Sul, Edição Especial n.54, p.<150-161>,jul./dez. 2019 
O método utilizado foi a narrativa coletiva e a autonarrativa (gravação dos encontros presenciais - coletivos/individuais e diários de bordo dos pesquisadores, e como propulsores as técnicas de brainstorming e cartografia dos registros para as intervenções buscando operar e produzir sentidos a partir das conversações formais e informais nos encontros presenciais.

Com esses tons, os pesquisadores segundo Passos e Barros (2000), observaram, acompanharam para se conhecer os desenhos dos vários momentos de transformações ônticas e epistemológicas pelos pesquisados e pesquisadores na constituição dos seus modos de atribuição de sentido à vida, pela imersão no plano da experiência.

Nesse sentido, a cartografia, buscou (re)fazer, (re)pensar os caminhos percorridos, possuindo em si a reversão do sentido de método, ou seja, "não mais um caminhar para alcançar metas prefixadas (metá-hódos), mas o primado do caminhar que traça, no percurso, suas metas. A reversão, então, afirma um hódos-metá.” (PASSOS; BARROS, 2012, p. 17)

Isto significou que a metodologia qualitativa (pesquisa-intervenção), unida ao método (narrativas/autonarrativas) e suas técnicas (brainstorming e cartografia), viabilizaram um estudo sistêmico com rigorosidade científica às observações e às compreensões dos modos de existir dos pesquisados. Ou seja, suas aprendizagens, seus padrões organizativos, configurando emergências por meio das noções teóricas que embasam a pesquisa-intervenção, oferecendo, conforme Oliveira et al (2012), conhecimentos de segunda ordem, pois pesquisador-observador e pesquisados-observadores, ao narrarem suas experiências, mergulharam numa processualidade circular, pois esses entendimentos retornam a eles de maneira recursiva, complexificando-os.

Por fim, ao explorarmos os modos de atribuição de sentido que os pesquisados dão aos seus mundos/realidades, aprendemos, para dar conta das contingências implicadas para aprender a viver outras relações cognitivo/emocionais nas ações da vida.

\section{Geração de dados: reflexões}

Entendemos que, no fluxo da investigação, os dados foram gerados continuamente, pelos sujeitos que vivenciaram a pesquisa. Ou seja, pelos pesquisadores e sujeitos pesquisados. Igualmente não organizamos os dados gerados a partir de categorias, mas sim, a partir de marcadores que contribuíram à compreensão dos dados gerados.

Portanto, apresentamos uma reflexão, a partir de extratos das narrativas coletivas e autonarrativas, da complexificação, do sofrimento e da auto-organização dos sujeitos envolvidos. Assim, apresentamos alguns extratos de narrativas dos sujeitos de pesquisa como forma de problematizar e refletir os marcadores citados. Afinal, a dimensão narrativa das 
histórias de vida é o que existe de mais estrutural nos atos humanos. (OLIVEIRA, 2016).

\section{- Sofrimento:}

O sofrimento está sendo aqui entendido como um estado de aflição severa, associado a acontecimentos que ameaçam a integridade de uma pessoa. Sofrimento exige consciência de si, envolvendo as emoções. Tem efeitos nas relações pessoais da pessoa, e gera um impacto no próprio corpo (OLIVEIRA, 2016).

Eu é que estou mais nervosa porque ainda não sei como lidar (com o W), porque isso de ele estar uma hora estar fazendo as coisas e outra hora parece que ele desaprende, isso não entra na minha cabeça, sabe? Porque eu me sinto bem né (cansada), faz uns quatro ou cinco dias que o $\mathrm{W}$ está muito agitado, ai eu fico agitada, ele vê que eu estou assim e ele fica mais ainda e cada dia que passa é pior. Eu tento tirar isso de mim, mas não consigo (Sujeito 1).

O sofrimento surge sempre associado a eventos, sobretudo externos, como algo que está acontecendo com outras pessoas, doença, desemprego, dentre outros. Ao mesmo tempo, este sofrimento pode gerar sintomas físicos, muito embora não seja somente isto que ele acarreta. A especificidade subjetiva do sofrimento humano verifica-se também pela possibilidade de ocorrer a partir de qualquer dimensão, ainda que quem sofra seja a pessoa no seu todo (OLIVEIRA, 2016).

Às vezes ele me sufoca, estar sempre junto do P... Eu sinto que preciso disso, tô muito cansada, cansada [...] (Sujeito 2).

É que eu acho que não estou aceitando o fato de que ele é diferente sabe? Às vezes eu me pergunto, por que eu, por que eu não posso ter tudo normal como os outros? A gente faz uma comparação, querendo ou não, a gente compara né. Ele tem a priminha dele, da mesma idade, acho que um mês a mais, e eu olho para ela e penso, porque eu não? Sabe? Comigo é tudo mais difícil, tu vê as pessoas levando a vida assim e tu ali, parece que nunca vai sair daquilo, como se eu tivesse no mar, nadando, nadando e não enxergando nada a frente. É assim que eu estou me sentindo (Sujeito 1).

Percebemos em ambos os extratos destacados que estes sujeitos, mães de crianças autistas, sofrem com a condição de seus filhos. Os extratos foram retirados de narrativas geradas quando do início dos atendimentos, momento no qual a angústia e o sofrimento dos sujeitos ainda eram muito evidentes e vivenciados de maneira muito intensa.

De acordo com Oliveira (2016), aprender com o sofrimento decorre de uma flexibilização lenta de padrões, que não pode levar a sua ruptura, sob risco de desagregação da identidade. Assim, é importante que, no caso desta pesquisa, os pesquisadores que atendiam as mães, assumissem uma postura de observação, a fim de contribuir para que os sujeitos pudessem identificar padrões de sofrimento - o que mais lhe afetavam e como lidar e superar em alguma medida estas vivências, sem correr o risco de perdê-las e perder suas identidades enquanto mães de crianças autistas. 


\section{- Complexificação:}

No processo de complexificação o sujeito vai investigando como foi se constituindo e distinguindo, claramente, o papel do conhecimento no processo, praticando uma autoobservação circular e emergente. Neste processo, se reconstrói e surgem fenômenos que são novos para ele (OLIVEIRA, 2016).

As coisas estão melhorando, com certeza. As coisas que eram todo dia, hoje são momentos. O que ele fazia todo dia, é uma vez por semana, não é sempre. Já tá mais amenizado [...] (Sujeito 1).

Quando eu tive ele, pra mim era tudo novo e também tudo normal. Hoje eu até estava lendo na internet, que eles (autistas) quando não se aconchegam no colo, não olham direito no olho e o W mamou no peito uma semana só e não quis mais, hoje eu entendo, porque eu sentia algo diferente, eu pensava que eu não sabia segurar ele direito, mas eu lendo aquilo, agora eu entendo o porque ele fazia aquilo. Mas eu pensava que eu não era uma boa mãe, que não sabia cuidar dele, aconchegar meu filho, entendeu. Ai hoje eu sei o porquê (Sujeito 1).

Importante observar que o sujeito consegue perceber mudanças e que estas ocorrem no próprio fluxo do viver. A complexificação se relaciona com a capacidade de observar a si mesmo e esforçar-se para mudanças de hábitos e de padrões, conforme excerto a seguir:

\footnotetext{
Então a gente vai se adaptando né, teve um período que ele acordava de noite chorando ele não deixa eu fazer nada. Meu Deus o que é!, até que um dia a gente percebeu queria estar agarradinho que ele se agarrar em mim porque tinha câimbras horríveis nas pernas, percebemos pois estava dormindo de pijama curto... Mas pra ti ver como é tenso essa semana também ele acordou um dia as 5:00 ele tem acordado super bem-humorado. daí ele veio com o coração tão acelerado, ele tinha tido um pesadelo e não sabia falar isso dói mas é o que a gente tem é a comunicação. Eu me pego calada, mas a gente passa a observar mais [...] (Sujeito 2).

Agora estou conseguindo entender que o P. consegue fazer um monte de coisas. Isto faz com que eu fique mais fazendo as minhas coisas e daí eu relaxo mais, estou mais leve e com vontade das coisas. É bonito ver que ele está em evolução (Sujeito 2).
}

O processo de complexificação destas mães está intimamente relacionado ao processo de complexificação de seus filhos autistas. Por vezes, ambos os processos se misturam, tendo o observador/pesquisador que intervir, no sentido de refletir com os sujeitos de que as questões estão relacionadas mas que cada um deve viver sua individualidade, sob pena de prejuízo de suas subjetividades.

\section{- Auto-organização:}

Para Maturana (2006), conhecer não é representação ou captação de uma realidade externa. Ele afirma, ao contrário, que os seres vivos são fechados à informação e abertos para a troca de energia. Neste sentido, somos os criadores de nós mesmos e o que vem de fora apenas nos perturba e não nos determina. (MATURANA, 2006). Assim, os membros do grupo vão pensando sobre si mesmos, se auto-organizando através das narrativas em exercícios metacognitivos, nos quais podem refletir sobre seus próprios processos, apropriando-se deles autopoieticamente. 
Para mim eu tinha no pensamento, que eu tinha que estar sempre do lado, claro que tenho, mas eu tenho que entender que ele também tem que aprender a fazer as coisas, pra ele viver e eu não ficar tão histérica. [...] Como eu te disse né, tudo veio para somar né. Agora que eu já escutei muita coisa que não presta sabe, ai eu já aprendi a fazer assim ó, o que é bom a gente escuta e deixa aqui, o que não é vai sair logo pelo outro ouvido já, para não poluir a cabeça sabe, é assim (Sujeito 1).

Este trecho tem relação com a autonomia do sujeito, que significa a autoconstituição e o entendimento complexo de que aprender é pôr em prática, isto é, viver o aprendido. Importante também nesta autonarrativa é o uso de metáforas de forma abdutiva com inferências sobre a virtualidade do ser como potência.

A auto-organização é o princípio de funcionamento da vida, considerada aqui como um sistema fechado de acordo com a teoria da Biologia da Cognição. (MATURANA; VARELA, 1997). Este fato nos leva a pensar em mecanismos auto-organizativos, que garantem a passagem de estados de indiferenciação para estados de construção de diferença, ou singulares e, portanto, portadores de significados para a vida. Neste processo, que é explicado pelo princípio de Von Foerster da "ordem pelo ruído", a entropia vai sendo revertida, o que aumenta a ordem interna do sistema. Todos estes fenômenos compõem um sistema que vai se complexificando.

Eu tô mais relaxada, deixando ele fazer mais as coisas por ele. Isto me dá mais tempo e percebo que ele é capaz. Estou aliviada e mais descansada porque vejo que ele pode fazer as coisas dele. E daí eu posso fazer as minhas (Sujeito 2).

A auto-organização cria mais caos (ruído), que vai sendo transformado em mais ordem, o que, por sua vez, cria novos ruídos e, assim, segue-se o processo vital numa espiral, cada vez mais complexa. O motor desta complexificação é o papel do observador situado no interior do sistema. Como resultado deste operar, surgem emergências que são constituintes do sistema.

Assim, as vivências dos sujeitos da pesquisa, familiares e pesquisadores/bolsistas, proporcionou, a partir das (auto)narrativas, o viver conhecer de processos que envolvem sofrimento, e por isto envolvem complexificação e auto-organização. O devir se apresenta como possibilidades de viver o sofrimento, conhecendo-o a partir de uma perspectiva complexa, por isto inundada de potência auto-organizativa.

\section{Perspectivas}

A partir das emergências descritas buscamos (re)pensar os desdobramentos da investigação, por meio das experiências envolvidas na metodologia complexa adotada. Nesse sentido, as conversações informais, autonarrativas, narrativas poderão instaurar reflexões para uma produção de sentidos que poderá contribuir efetivamente para a elaboração de uma 
epistemologia da complexidade.

A abordagem do sofrimento de famílias com sujeitos diagnosticados com TEA, que se configura em um objeto complexo de pesquisa, precisa ser tratada e entendida de maneira igualmente complexa, ou seja, articulando todas as suas dimensões. Assim, o mesmo sofrimento que por vezes pode comprometer a autonomia dos sujeitos, permite sua autoorganização, complexificando-os.

O trabalho com as narrativas e com as autonarrativas possibilita que os sujeitos da pesquisa, familiares e pesquisadores, enxerguem-se como plenos de capacidades e possibilidades de reinventar-se e redescobrir-se a todo instante, entendendo o sofrimento de maneira complexa e não linear, enquanto possibilidades e não apenas enquanto obstáculo.

Por conseguinte, as ações descritas poderão convergir para reflexões sobre a educação de forma complexa, isto é, unir as dimensões que foram cindidas e que marcam a cultura da modernidade. Além disto, o trabalho desta pesquisa visa contribuir para que as famílias possam (re)organizar-se a partir das reflexões sobre as vivências dentro de suas realidades/mundos.

\title{
(AUTO) NARRATIVES IN / IN THE FAMILY: COGNITION AND EMOTION
}

\begin{abstract}
The analysis presented in this article starts from the actions developed in the research "At your fingertips: the iPad as a complex instrument of cognition / subjectivation", bringing with it the theoretical vectors of the research group, built from the convergence between "education and complexity". Therefore, the understandings that configure the analysis are linked to the Complexity Paradigm and the Autopoiesis Theory. The proposed methodology is qualitative, based on intervention research, involving subjects who accompany children with Autistic Spectrum Disorders (ASD). The instruments used were the collective and selfnarrative narratives as propellers of interventions, producing meanings through formal and informal conversations in face-to-face meetings. The described actions converge to reflections on the learning process in a complex way, that is, uniting the cognition / emotions dimensions, which were split and that mark the culture of modernity. In the end, the work aims to contribute so that families can (re) organize from the reflections on the experiences within their realities / worlds.
\end{abstract}

Keywords: Complexity; self-organization; cognition / emotions; self-narrative; families; TEA.

\section{REFERÊNCIAS}

CAVAlCANTI, A. E. Construções e desconstruções. São Paulo: Casa do Psicólogo, 2007.

DAMÁSIO, A. O Mistério da Consciência: do corpo e das emoções ao conhecimento de si. São Paulo: Companhia das Letras, 2000. 
FOUCAULT, M. Conversa com Michel Foucault. In:

Repensar a política/Ditos e

Escritos VI. Rio de Janeiro: Forense Universitária, 2010, p. 289-347.

GADIA, C. Aprendizagem e Autismo. In: ROTTA, N. T.; OHLWEILER, L.; RIESGO, R. dos S. Transtornos da aprendizagem abordagem neurobiológica e multidiciplinar. Porto Alegre: Artmed, 2006. p. 423-433.

MATURANA, H. Cognição, Ciência e Vida Cotidiana. Belo Horizonte: Editora UFMG, 2006.

MATURANA, H.; VARELA, F. J. A Árvore do Conhecimento: as bases biológicas do entendimento humano. São Paulo: Editorial PSI, 1995.

De Máquinas e Seres Vivos: autopoiese: a organização do vivo. 3. ed., Porto Alegre: Artes Médicas, 1997.

MATURANA, H.; VERDEN-ZOLLER, G. Amar e brincar: fundamentos esquecidos do humano. São Paulo: Palas Athena, 2004.

OLIVEIRA, C. C. et al. Aprendizagem e sofrimento: narrativas. Santa Cruz do Sul: EDUNISC, 2012.

OLIVEIRA, C. C. Para compreender o sofrimento humano, Rev. Bioét., v. 24, n. 2, p. $225-$ 234, 2016.

PASSOS, E.; BARROS, R. A construção do plano da clínica e o conceito de transdisciplinaridade, Psicologia: Teoria e Pesquisa, v. 16, $\mathrm{n}^{\circ} .1,71-79$, jan.-abr., 2000.

A cartografia como método de pesquisa-intervenção. In: Pistas do método da cartografia: pesquisa-intervenção e produção de subjetividade. Porto Alegre: Sulina, 2012.

SOUZA, P. Agenciar. In: FONSECA, Tania M. G.; NASCIMENTO, Maria L. do; MARASCHIN, Cleci. Pesquisar na diferença: um abecedário. Porto Alegre: Sulina, 2012.

STENGERS, I. A invenção das ciências modernas. São Paulo: Edições 34, 2002.

\section{Sobre os autores:}

Maira Meira Pinto é graduada em Serviço Social, pela PUC/RS, tem Mestrado em Serviço Social e Doutorado em Educação, ambos pela mesma Instituição. É professora na UNISC, onde atua como professora e pesquisadora, pesquisando sobre Responsabilidade Social Universitária e temáticas relacionadas à teoria da auto-organização e complexidade. Endereço Eletrônico: mairap@unisc.br

César Augusto Muller é Graduado em Orientação Educacional, Licenciatura Plena pela UNISC, Mestre em Desenvolvimento Regional pela UNISC e Doutor em Educação pela PUC/RS. É professor na UNISC. Endereço Eletrônico: cesar@unisc.br 